\title{
Exploring the Links between Comics Translation and AVT
}

For a very young but steadily developing subfield of Translation Studies such as the translation of comics it seems only natural to look to other research areas within the discipline for inspiration and research methods. This is also one of the aims of the present article, which will attempt to point to certain similarities between comics translation and the subdiscipline of Translation Studies known as AVT (Audiovisual Translation) and the field of subtitling in particular. Both films and comic books are multimodal texts based on the interplay between the verbal and the visual. What is more, both films and comic books are primarily based on dialogue, which is nevertheless transcribed and communicated in writing in both subtitled films and translated comics. Text will, in both cases, usually appear in clearly specified areas, that is at the bottom of the screen (with some exceptions) in subtitled films, and in speech balloons (with some exceptions) in the case of comics. Furthermore, text may be condensed due to the existence of spatial and technical constraints, such as the limited number of characters that may appear at the bottom of the screen or the size of speech balloons and the type of the lettering employed in the case of comics. It is particularly the latter aspect, that is textual condensation related to both spatial constraints and the multimodal character of comics, that the article will focus on, investigating the first Polish translations of Calvin and Hobbes comic strips created by the American cartoonist Bill Watterson. 